\title{
For the Good Times
}

\section{Imre Benedek}

"George Emil Palade" University of Medicine, Pharmacy, Sciences and Technology, Târgu Mureș, Romania

Acute myocardial infarction continues to represent a devastating disease. In spite of many significant advances in the therapy of ischemic heart diseases, an effective method to recover damaged myocardium has not been validated so far.

More than ten years ago, transplantation of bone marrow stem cells into the infarcted area was proposed in the hope that angiogenic properties of the stem cells can lead to regeneration of myocardial tissue and may trigger the development of new, viable myocardial cells that will replace the scar tissue.

This challenging hypothesis has been tested in an impressive number of clinical trials, all of them showing promising results. ${ }^{1}$ However, none of these trials led to a real revolution in the therapy of acute myocardial infarction, as expected, mainly because they did not succeed to demonstrate a significant impact on survival.

In 2007, in Târgu Mureș, an interdisciplinary team led by Prof. István Benedek and myself, performed the first stem cell transplantation in a patient suffering from myocardial infarction. Prof. István Benedek was the Head of the Clinic of Hematology and was the champion who performed the first stem cell transplantation in an adult with a hematological disorder in Romania. Working together, we performed a series of stem cell transplantations in patients with acute myocardial infarction or with critical limb ischemia with very good results, demonstrating that an effective collaboration between the two disciplines can lead to a significant progress for both and can expand the horizons of medicine.

In a follow-up study published after 6 years, using CT imaging performed at 4 years after the transplantation, we demonstrated that the infusion of stem cells in the infarcted coronary artery can also play a protective role, preventing atherosclerosis progression. ${ }^{2}$ At 4 years after the stem cell infusion, plaque volume (PV) and coronary calcium (CC) accumulation were significantly lower in the group who received stem cells compared to the control group, at the level of the entire coronary tree (PV 702 $\mathrm{mm}^{3}$ vs. $1,465 \mathrm{~mm}^{3}, \mathrm{p}=0.0006$; CC score 295 vs. 796, $\mathrm{p}<0.0001)$ and at the level of the coronary segment as well (coronary PV $112.12 \pm 16.82 \mathrm{~mm}^{3}$ for the treated arteries vs. $189.56 \pm 20.98 \mathrm{~mm}^{3}$ for the untreated arteries, $\mathrm{p}<0.0001$, and mean CC score $53.12 \pm 16.4$ vs. $106.43 \pm$ 10.86, $\mathrm{p}<0.0001)$.

At the same time, in our experience, patients with critical limb ischemia who received stem cell infusion in the ischemic limb and in the affected peripheral artery, reported a significant relief in symptoms, which was persistent after 4 years.

Our work shows that an interdisciplinary approach that facilitates a revolutionary treatment may save lives and may improve the quality of life. This is, after all, the goal of our activity in the medical field. Unfortunately, this did not work for Prof. István Benedek. He died on September1, 2020, at the age of 71, after contacting COVID-19 while he was working in the front line in the Clinic of Hematology, a clinic that he created.

\section{CONFLICT OF INTEREST}

Nothing to declare.

In loving memory of my brother, Prof. István Benedek, head of the Clinic of Hematology of Târgu Mureș 

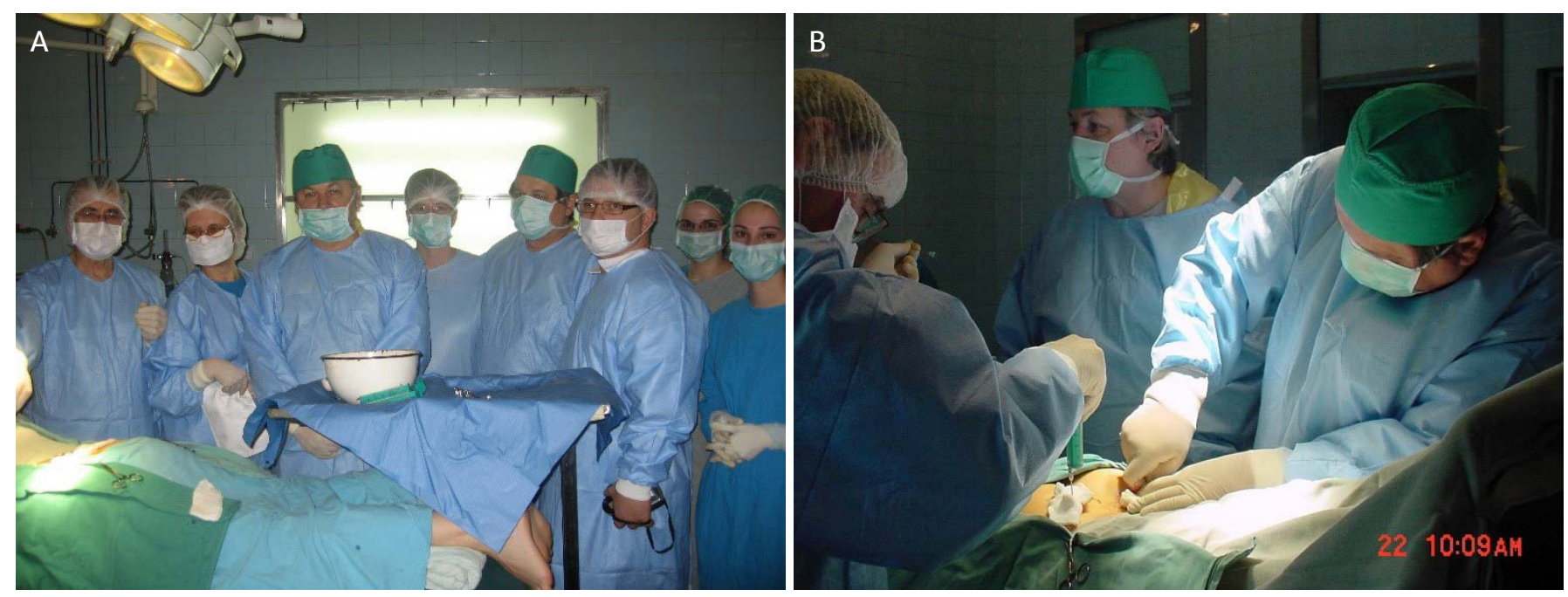

FIGURE 1. March, 2007. The interdisciplinary team led by Prof. Imre Benedek (third from the left in panel A and at the left in panel B) and Prof. István Benedek (fourth from the right in panel A and at the right in panel B) while performing the first stem cell transplantation in Romania in a patient suffering from myocardial infarction

\section{REFERENCES}

1. Pavo N, Charwat S, Nyolczan N, et al. Cell therapy for human ischemic heart diseases: critical review and summary of the clinical experiences. J Mol Cell Cardiol. 2014;75:12-24. doi: 10.1016/j.yjmcc.2014.06.016

2. Benedek I, Bucur O, Benedek T. Intracoronary infusion of mononuclear bone marrow-derived stem cells is associated with a lower plaque burden after four years. J Atheroscler Thromb. 2014;21:217-219. doi: 10.5551/jat.19745. 